\title{
The SENECA study: potentials and problems in relating diet to survival over 10 years
}

\author{
Wija A van Staveren*, Lisette CPMG de Groot and Annemien Haveman-Nies \\ Wageningen University, Department of Agrotechnology and Food Sciences, Division of Human Nutrition and \\ Epidemiology, PO Box 8129, 6700 EV Wageningen, The Netherlands
}

\begin{abstract}
Objective: To give an overview of the evaluation of the modified diet history applied in the SENECA study (Survey in Europe on Nutrition and the Elderly; a Concerted Action).

Design: Nineteen centres in 12 countries participated at baseline. Nine of these SENECA centres conducted a repeat measurement scheme in elderly people born between 1913 and 1918. These longitudinal centres included 100 subjects per sex per site.

Methods: The relative validity of the method was tested by comparing results of the modified diet history with results obtained from a weighed record in 82 subjects. In the follow-up we compared changes in energy intake with changes in body weight and calculated the physical activity ratio in all longitudinal centres. In SENECA's finale we examined the predictive value of dietary patterns observed at baseline for survival 10 years later, making use of the original and an adapted Mediterranean Diet Score. Results: The modified diet history overestimated intake, compared with the weighed record. However, the physical activity ratio and an in-depth study in a metabolic room indicated that the diet history rather underestimated energy intake. We did not find a relationship between changes in energy intake and changes in body weight, but this could be explained by the fact that most likely we did not measure intake in the dynamic phase of body weight change. Based on the adapted Mediterranean Diet Score, the study results showed a positive relation between a healthy diet and survival.

Conclusion: We conclude that the modified diet history has given sufficiently reliable results for the purposes of the study.
\end{abstract}

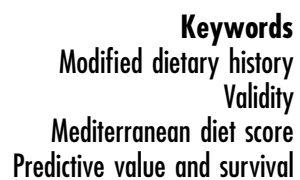

Keywords

Validity

Predictive value and survival
In 1988, a European multi-centre study named SENECA (Survey in Europe on Nutrition and the Elderly; a Concerted Action) was initiated in people born between 1913 and 1918. Nine of the original 19 towns participating in 12 European countries decided to continue the longitudinal study by conducting a second survey in 1993 and a finale in 1999. The aim of SENECA's finale was to identify dietary and lifestyle factors important for survival and the maintenance of health of SENECA participants since 1988.

In nutritional epidemiology, longitudinal studies are expected to be easier and more fruitful in older adults for several reasons. One reason, amongst others, is that people tend to have fairly definite likes and dislikes so that their diet is likely to be more uniform (and may therefore be more easily characterised) with ageing than that of younger persons. Nutritional deficiency is more common at older ages than at other periods in life, yet many elderly people eat well. The dietary variation between individuals is therefore expected to be large in comparison with the variations within individuals. Furthermore, due to increased morbidity and mortality, endpoints in the older category will occur per person year of follow-up more often than at younger ages ${ }^{1}$.

However, it is well known that there are also problems in surveying older people ${ }^{2}$. Fading memory is a problem in older adults for reporting on food consumption patterns. Physical disabilities may require special equipment, for instance in recording dietary intake. A high proportion of non-responders and dropouts in the course of the study is often observed, which may lead to selectivity. Co-morbidity makes it difficult to diagnose diseases and to distinguish relationships between diet and disease from relationships between diet and ageing ${ }^{3}$.

In this paper, the experience gained from the SENECA study is used to illustrate the problems related to dietary assessment in different stages of longitudinal research. Evaluation of the applied method at baseline and followup is discussed and the predictive value of the observed intakes for survival examined. 


\section{Design and methods}

For a full description of the design and methods we refer the reader to SENECA's manual of operations ${ }^{4}$. The design was a repeat measurement scheme with measurements stratified for sex and age taken at three times (1988/89, 1993 and 1999). A non-responder's questionnaire was included in the measurement scheme. This design allowed for the study of age, period and cohort effects.

\section{Subjects and setting}

At baseline, a total of 2586 elderly people, who were born between 1913 and 1918, were selected from 19 towns in 12 European countries: Hamme in Belgium; Roskilde in Denmark; Chateau Renault-Amboise, Haguenau and Romans in France; Anogia-Archanes and Markopoulou in Greece; Monor in Hungary; Padua and Fara SabinaMagliano Sabina-Poggio Mirteto in Italy; Culemborg in the Netherlands; Elverum in Norway; Marki in Poland; Coimbra and Vila Franca de Xira in Portugal; Betanzos in Spain; and Yverdon, Burgdorf and Bellinzona in Switzerland. In 1993, 1170 subjects from the nine towns in italics were re-examined at age 74 to 79 years. A final assessment of health, survival and date and cause of death in the nine 'longitudinal' towns of those who did not survive up to 1999 concluded the SENECA study.

\section{Dietary assessment}

A modified dietary history was used to estimate food intake. This method comprised two parts: a 3-day record and a meal-based list of foods to check the usual consumption of the previous month. Portion sizes were based on standard portion sizes or checked by weighing. Usual food intake was converted into nutrients by local food composition tables (see Moreiras-Varela et al. ${ }^{5}$ for references for these food composition tables). The 3-day estimated record was included to make subjects conscious of their food intake. In five centres the record was also used to evaluate the results obtained with the checklist of foods and to estimate day-to-day variation ${ }^{6}$.

For organising foods into food groups and subgroups on the basis of their origin, composition or function in the diet, the Eurocode system was used ${ }^{7}$. Foods were grouped as follows: milk and milk products (excluding butter); eggs and egg products; meat and meat products; fish, molluscs, reptiles and crustaceans and their products; oils and fats (including butter); grain and grain products; vegetables; fruits; sugar, chocolate and confectionery.

A diet score based on the Mediterranean Diet Score (MDS) developed by Trichopoulou et al. ${ }^{8}$ was applied. Intake values were adjusted to daily intakes of $10.5 \mathrm{MJ}$ $(2500 \mathrm{kcal})$ for men and $8.4 \mathrm{MJ}$ (2000 kcal) for women. The sex-specific median intake values of the food items were used as cut-off points. For each component of the MDS, if the subject's intake was comparable to the Mediterranean diet it was coded one, and if the intake was not in agreement with the Mediterranean diet it was coded zero. Based on the literature we came to an adapted Mediterranean Diet Score? ${ }^{9}$ The most important adaptations were:

- optimal intake for milk and milk products was defined as between the 25 th and 75 th percentile values instead of an intake below the median intake;

- in women the upper limit of meat and poultry was raised to $130 \mathrm{~g} \mathrm{day}^{-1}$ (slightly lower than the 75 th percentile) instead of below the median; and

- the upper limit of intake of alcohol beverages for women was increased from the median $(0 \mathrm{~g})$ to the value at the 75 th percentile $\left(8 \mathrm{~g} \mathrm{day}^{-1}\right)$.

Table 1 gives the food components included and the criteria applied. The potential score range is $0-7$; the higher the score, the better the supposed effect on health and consequently on survival.

\section{Evaluation of the dietary method}

We used various approaches to assess the modified diet history. We compared our method with a weighed diet record ${ }^{10}$, and we examined the validity with an independent standard ${ }^{11}$. We looked into the reproducibility and the correlations of changes in intake with changes in weight ${ }^{12}$. Finally we examined whether the observed intakes predicted survival as expected from earlier surveys.

\section{Statistical analysis}

Descriptive statistics were calculated using the SAS statistical package (SAS Institute, Inc., Cary, NC, USA).

Table 1 Food components and cut-off values of the adapted Mediterranean Diet Score (Haveman-Nies et $a .^{9}{ }^{9}$ )

\begin{tabular}{|c|c|c|}
\hline Food/nutrient item & Men & Women \\
\hline $\begin{array}{l}\text { Ratio of monounsaturated to saturated fat } \\
\text { Grains } \\
\text { Fruits and products and vegetables } \\
\text { Legumes/nuts/seeds } \\
\text { Alcoholic beverages } \\
\text { Meat and poultry } \\
\text { Milk and milk products }\end{array}$ & $\begin{array}{l}>P_{50}(1.00) \\
>P_{50}\left(235 \text { g day }^{-1}\right) \\
>P_{50}\left(548 \text { day }^{-1}\right) \\
>P_{50}\left(4 \text { day }^{-1}\right) \\
<P_{50}\left(13 \text { gday }^{-1}\right) \\
<P_{50}\left(134 \text { g day }^{-1}\right) \\
P_{25}-P_{75}\left(144-474 \text { gay }^{-1}\right)\end{array}$ & $\begin{array}{l}>P_{50}(1.00) \\
>P_{50}\left(186 \mathrm{~g} \mathrm{day}^{-1}\right) \\
>P_{50}\left(524 \mathrm{gday}^{-1}\right) \\
>P_{50}\left(2 \mathrm{gday}^{-1}\right) \\
<P_{75}\left(8 \mathrm{gay}^{-1}\right) \\
<\sim P_{75}\left(130 \mathrm{gday}^{-1}\right) \\
P_{25}-P_{75}\left(159-465 \mathrm{~g} \text { day }^{-1}\right)\end{array}$ \\
\hline
\end{tabular}

$\mathrm{P}_{25}, \mathrm{P}_{50}, \mathrm{P}_{75}-25$ th, 50th (median) and 75 th percentiles. 
The relationship between change in diet and change in body weight was examined with a linear regression model, accounting for baseline values and changes in scores of smoking, physical activity, chronic disease, activities of daily living (ADL) and sex. Cox proportional hazards (survival) analysis was used to investigate associations between diet (including MDS and single food components) and all-cause mortality ${ }^{13}$. Adjustments were made for age at baseline, physical activity, smoking, region and serum albumin level.

\section{Results}

\section{Participants}

In 1999 we could detect the vital status of $96 \%$ of the population. Eighty-four of the 2199 participants were lost to follow-up. The percentage of deceased persons was higher in men than in women and varied between centres (Table 2). In 1996, van't Hof and Burema ${ }^{14}$ reported that selectivity in participation was apparent in most towns regarding the items 'own health judgement' and 'relatively physically active compared to others', indicating that we dealt with the more healthy group of elderly people.

\section{Evaluation of the adapted dietary history method}

Regarding the level of intake, we compared the results of a weighed record with results of the diet history for 82 subjects from seven centres. We observed that the data from the history were consistently higher; expressed as a percentage of the weighed record, the mean differences varied from 1\% (cholesterol) to 28\% (mono- and disaccharides) ${ }^{10}$. However, a comparison of energy intake with energy expenditure as measured with indirect calorimetry in 12 elderly people indicated underreporting

Table 2 Number of participants per SENECA centre and percentage deceased

\begin{tabular}{lccccc}
\hline & \multicolumn{3}{c}{ Men } & & \multicolumn{2}{c}{ Women } \\
\cline { 2 - 3 } \cline { 5 - 6 } Centre $^{*}$ & Total, $n$ & Deceased (\%) & & Total, $n$ & Deceased (\%) \\
\hline H/B & 126 & 56 & & 105 & 29 \\
R/DK & 101 & 54 & & 101 & 36 \\
H/F & 109 & 54 & & 110 & 23 \\
R/F & 142 & 54 & & 137 & 23 \\
P/I & 97 & 48 & & 93 & 22 \\
C/NL & 114 & 59 & 124 & 32 \\
V/P & 111 & 46 & 111 & 33 \\
B/E & 88 & 49 & & 119 & 28 \\
Y/CH & 123 & 48 & & 126 & 25 \\
Bu/CH & 30 & 47 & & 30 & 23 \\
Be/CH & 30 & 47 & 30 & 38 \\
M/PL & 19 & 67 & 23 & 36 \\
Total & 1090 & 52 & 1109 & 28 \\
\hline
\end{tabular}

${ }^{*} \mathrm{H} / \mathrm{B}$ - Hamme (Belgium); R/DK - Roskilde (Denmark); H/F - Chateau Renault-Amboise, Haguenau (France); R/F - Romans (France); P/I Padua (Italy); C/NL - Culemborg (The Netherlands); V/P - Vila Franca de Xira (Portugal); B/E - Betanzos (Spain); Y/CH - Yverdon (Switzerland); $\mathrm{Bu} / \mathrm{CH}-$ Burgdorf (Switzerland); Be/CH - Bellinzona (Switzerland); M/PL - Marki (Poland). of about $12 \%$ by the diet history ${ }^{11}$. Also, according to criteria of $\mathrm{FAO} / \mathrm{WHO} / \mathrm{UNU}^{15}$, group means of daily energy intake should exceed 1.4 times basal metabolic rate (BMR). On the basis of BMR values, women in seven centres had intakes below the required levels according to FAO/WHO/UNU. Such low levels may be either an underestimation of intakes or true and real values. If the values reflect real habitual intake, there should be a relationship between low intakes and losing weight. However, linear regression analyses accounting for sex, baseline value and change in smoking habits, subjective health, number of chronic diseases, ADL score and relative activity did not show a relationship between change in weight and change in energy intake over 4 years ${ }^{12}$.

The reproducibility of the diet history was tested in younger age groups and showed correlation coefficients between 0.8 and 0.9, which is acceptable. The SENECA study did not confirm the expected relatively low withinperson variation and high between-person variation in our elderly group ${ }^{12}$. The ratio of within-person to betweenperson variation in intake of energy in the SENECA study was 0.7 , as calculated from the 3-day estimated record, and appeared to be lower than the value of 1.2 observed by Beaton et $a l^{16}$ in a group of younger adults with three repeats of a 24-hour food recall. However, for most nutrients, differences disappeared when corrected for energy intake. In SENECA's finale study we looked into the predictive value for survival of the original and adapted Mediterranean Diet Score (oMDS and aMDS, respectively). Table 3 shows the data for the total scores as well as the specific food items making up that score. As is shown in Table 3, the aMDS coincided with improved survival time

Table 3 Hazard ratio $(\mathrm{HR})^{*}$ estimates and 95\% confidence intervals $(95 \% \mathrm{Cl})$ of single food items of the original (oMDS) and adapted (aMDS) Mediterranean Diet Score, for male and female participants of the SENECA population

\begin{tabular}{lcc}
\hline & $\begin{array}{c}\text { Men }(n=631) \\
\text { HR }(95 \% \mathrm{Cl})\end{array}$ & $\begin{array}{c}\text { Women }(n=650) \\
\text { HR }(95 \% \mathrm{Cl})\end{array}$ \\
\hline $\begin{array}{l}\text { Ratio of monounsaturated } \\
\quad \text { to saturated fat }\end{array}$ & $0.87(0.67-1.15)$ & $0.88(0.61-1.25)$ \\
Grains & $0.80(0.63-1.02)$ & $1.00(0.73-1.38)$ \\
Fruits and products & $0.97(0.76-1.22)$ & $1.08(0.78-1.49)$ \\
Vegetables & $1.10(0.88-1.39)$ & $0.99(0.72-1.36)$ \\
Legumes/nuts/seeds & $0.97(0.76-1.22)$ & $1.07(0.78-1.46)$ \\
Alcoholic beverages & $1.17(0.93-1.47)$ & $1.18(0.86-1.62)$ \\
Meat and poultry & $0.74(0.58-0.94)$ & $1.35(0.98-1.86)$ \\
Milk and milk products & $0.92(0.73-1.15)$ & $1.12(0.83-1.53)$ \\
oMDS† & $0.94(0.74-1.19)$ & $1.09(0.78-1.54)$ \\
Fruits and products and & $1.04(0.83-1.31)$ & $0.89(0.65-1.22)$ \\
$\quad$ vegetables & & \\
Alcoholic beverages & $1.17(0.93-1.47)$ & $0.91(0.63-1.30)$ \\
Meat and poultry & $0.74(0.58-0.94)$ & $1.17(0.84-1.64)$ \\
Milk and milk products & $1.01(0.81-1.27)$ & $0.68(0.50-0.93)$ \\
aMDS $\ddagger$ & $0.74(0.55-1.00)$ & $0.79(0.55-1.13)$
\end{tabular}

${ }^{*} \mathrm{HR}$ adjusted for age at baseline, physical activity, smoking, region and serum albumin level.

† oMDS: cut-off values $\leq 3,>3$.

$\ddagger$ aMDS: cut-off values $\leq 4,>4$ 
Table 4 Hazard ratio (HR) estimates and 95\% confidence intervals $(95 \% \mathrm{Cl})$ derived from Cox models* with milk consumption as predictor of survival, for male and female participants of the SENECA population

\begin{tabular}{|c|c|c|}
\hline & $\begin{array}{l}\text { Men }(n=631) \\
\operatorname{HR}(95 \% \mathrm{Cl})\end{array}$ & $\begin{array}{c}\text { Women }(n=650) \\
\text { HR }(95 \% \mathrm{Cl})\end{array}$ \\
\hline \multicolumn{3}{|l|}{ North } \\
\hline o-milk† & $0.86(0.65-1.14)$ & $1.02(0.69-1.51)$ \\
\hline a-milkł & $1.01(0.77-1.34)$ & $0.79(0.54-1.15)$ \\
\hline \multicolumn{3}{|l|}{ South } \\
\hline o-milk† & $0.98(0.66-1.46)$ & $1.38(0.82-2.33)$ \\
\hline a-milkł & $1.07(0.72-1.59)$ & $0.52(0.30-0.91)$ \\
\hline
\end{tabular}

${ }^{*}$ Model adjusted for age, smoking and physical activity. †o-milk: cut-off value $<$ median intake.

$\ddagger$ a-milk: cut-off value between 25 th and 75 th percentile.

in men and women although the values did not reach significance in women. The individual food items did not give a clear picture on their predictive value. In women, the adaptations to alcohol, meat and milk resulted in more favourable scores for the three items. Table 4 gives the hazard ratios for milk as observed in the centres in northern and southern Europe. The table shows that, especially for women in the south, the predictive value improved after the adaptation we made for milk; however, for men the picture was less clear. We were not able to explain this difference by the amounts of milk consumed in the different centres.

In the southern centres, the mean MDS was generally better than the mean score observed in the northern centres. Table 5 shows the mean scores of these centres and the predictive value of both scores for survival. The oMDS did not seem to go with a beneficial effect on survival when eating according to this score. After adaptation, however, for men and women in north and south Europe, the hazard ratios for all groups pointed in the same direction: a favourable score is related to a better survival time.

\section{Discussion}

The purpose of this paper was to give an overview of the evaluation of the modified diet history applied in the SENECA study at baseline, the follow-up and in the finale. At baseline we found that the modified diet history overestimated intakes compared with the weighed record. However, an in-depth study showed that when energy intake was compared with energy expenditure as observed in a metabolic room, even the diet history appeared to be underestimating energy intake.

Such a systematic error might not disturb relationships with disease, changes in body weight and survival as long as it is constant over time and in the different subgroups. That we were not able to find a relationship between changes in body weight and energy intake over a period of 4 years is not surprising. First, very small differences in mean daily energy intake would need to be detected to be able to find such a relationship. In an earlier paper $^{12}$, we calculated that in the dynamic phase of losing weight amounting to $500 \mathrm{~g} \mathrm{month}{ }^{-1}$, the subject would need to decrease energy intake by an average of $320 \mathrm{~kJ} \mathrm{day}^{-1}$, assuming that all other determinants of the energy balance are constant. Based on our reproducibility study we calculated that with a sample size of 100 subjects, at a probability level of 5\%, the power of the test to detect a difference of $420 \mathrm{~kJ}$ is $80 \%$. Thus, for the given sample sizes the reproducibility of our method is fair, but for this problem not sufficiently reliable. A more important reason for not finding the relationship might be the fact that the majority of people were most likely not in the dynamic phase of losing weight during the period of dietary assessment. Overall, when we compare the results of the validation and reproducibility study of our diet history adapted for elderly people with the diet history applied in younger populations, we think that the errors observed are comparable ${ }^{2}$.

Several diet scores have been developed to measure overall dietary quality. Until now the European scores have not been validated. Haveman-Nies et al. ${ }^{9}$ made an attempt by relating the diet scores to the individual diet components. From the lowest to the highest scores, the mean intakes of all individual components improved in both MDS. This suggests that the MDS are reliable

Table 5 SENECA Mediterranean Diet Score (MDS) as predictor of survival time: hazard ratio (HR) estimates and $95 \%$ confidence intervals $(95 \% \mathrm{Cl})$ derived from Cox models*

\begin{tabular}{|c|c|c|c|c|c|c|}
\hline & \multicolumn{3}{|c|}{$\operatorname{Men}(n=631)$} & \multicolumn{3}{|c|}{ Women $(n=650)$} \\
\hline & $n$ & Mean score & $\mathrm{HR}(95 \% \mathrm{Cl})$ & $n$ & Mean score & $\mathrm{HR}(95 \% \mathrm{Cl})$ \\
\hline North & 391 & & & 392 & & \\
\hline oMDS† & & 3.4 & $0.91(0.69-1.21)$ & & 3.5 & $0.95(0.64-1.40)$ \\
\hline aMDS $\ddagger$ & & 2.9 & $0.78(0.50-1.20)$ & & 3.5 & $0.68(0.40-1.16)$ \\
\hline South & 241 & & & 258 & & \\
\hline oMDS† & & 4.8 & $1.06(0.63-1.77)$ & & 4.8 & $1.85(0.74-4.65)$ \\
\hline aMDS $\ddagger$ & & 4.3 & $0.73(0.48-1.10)$ & & 4.5 & $0.90(0.54-1.51)$ \\
\hline
\end{tabular}

* Model adjusted for age, smoking, physical activity and serum albumin level.

† oMDS - original Mediterranean Diet Score.

$\ddagger$ aMDS - adapted Mediterranean Diet Score. 
indicators of dietary quality. Another way to test this is by looking at the predictive value of these scores for disease and survival. In an earlier study, Haveman-Nies et $a l^{9}$ found a positive relationship between MDS and other healthy lifestyle variables such as non-smoking, greater physical activity and less body fatness. In the present study we showed a positive relationship between favourable scores on the adapted MDS and survival for centres in the north and south of Europe and for men and women. The hazard ratios did not reach statistical significance. For the aMDS, as observed in all men and women participating in SENECA, this might be due to a certain over-correction by taking 'centre' in our model and thereby diminishing the true association between diet and survival. However, if this factor had been disregarded no adjustments would have been made for confounding, non-diet-related differences across sites.

For the specific items in the diet scores, the predictive value for survival is also less consistent after adaptation and when studied for the two regions. We have worked this out for milk and milk products. We could not explain this inconsistency based simply on differences in mean and variation of amounts consumed per site of these products. Several other factors may play a role in the inconsistent values and work in concert. First, within this group of products there are more and less healthy variants, e.g. low-fat versus whole milk. With the Eurocode we could not distinguish between these products. Also, the preparation method and the place of the product in the daily diet might affect the healthiness of use of such a product group and the MDS does not take that into account. A common European food composition table would have been of great value in improving the MDS. Further, other regional differences affecting survival may play a role and interact, causing inconsistencies in outcomes.

In conclusion, the adapted diet history for elderly people as applied in SENECA has given sufficiently reliable results for the purposes of the study, namely to describe the variety in dietary patterns among the participating centres and to identify dietary factors predicting health and survival. In the future, a common European food composition table would be of great help for multi-centre studies in Europe.

\section{References}

1 Burr ML. Cohort studies. In: Margetts BM, Nelson M, eds. Design Concepts in Nutritional Epidemiology. Oxford: Oxford University Press, 1991.

2 Van Staveren WA, de Groot CPGM, Blauw YH, van der Wielen RPJ. Assessing diets of elderly people: problems and approaches. Am. J. Clin. Nutr. 1994; 59(Suppl.): 221S-3S.

3 Weinsier RL, Heimburger DC. Distinguishing malnutrition from disease: the search goes on. Am.J. Clin. Nutr. 1997; 66: 1063-4.

4 De Groot LCPGM, van Staveren WA, eds. Nutrition and the Elderly: Manual of Operations, November 1988. EURO-NUT Report 11, Wageningen: EURO-NUT, 1988.

5 Moreiras-Varela $\mathrm{O}$, van Staveren WA, Amorim Cruz JA, Carbajal A, De Henauw S, Grunenberger F, et al. Longitudinal changes in intake of energy and macronutrients of elderly Europeans. Eur. J. Clin. Nutr. 1996; 50(Suppl. 2): S67-76.

6 Van Staveren WA, Burema J, Livingstone MBE, van den Broek T, Kaaks R. Evaluation of the dietary history method used in the SENECA study. Eur.J. Clin. Nutr. 1996; 50(Suppl. 2): $\$ 47-55$.

7 Kohlmeier L, Poortvliet EJ. Eurocode 2 Food Coding System, version 92/1. Berlin: Institute for Social Medicine and Epidemiology, 1992.

8 Trichopoulou A, Kouris-Blazos A, Wahlqvist ML, Gnardellis $\mathrm{C}$, Lagiou $\mathrm{P}$, Polychronopoulos E, et al. Diet and overall survival in elderly people. Br. Med. J. 1995; 11: 1457-60.

9 Haveman-Nies A, Tucker KL, de Groot LCPGM, Wilson PW, Van Staveren WA. Evaluation of dietary quality in relationship to nutritional and lifestyle factors in elderly people of the US Framingham Heart Study and the European SENECA study. Eur. J. Clin. Nutr. 2001; 55: 870-80.

10 Nes M, van Staveren WA, Zajkas G, Inelmen EM, MoreirasVarela $\mathrm{O}$. Validity of the dietary history method in elderly subjects. Eur. J. Clin. Nutr. 1991; 45(Suppl. 3): S97-104.

11 Visser M, de Groot LCPGM, Deurenberg P, van Staveren WA. Validation of the dietary history method in a group of elderly women using measurements of total energy expenditure. $\mathrm{Br}$. J. Nutr. 1995; 74: 775-85.

12 Van Staveren WA, Burema J, de Groot CPGM. The SENECA study: potentials and problems in assessing dietary changes over time. Int. J. Sports Med. 1997; 18(Suppl. 3): S195-9.

13 Kleinbaum DG. Survival Analysis: A Self-Learning Text. New York: Springer-Verlag, 1996.

14 Van't Hof MA, Burema J. Assessment of bias in the SENECA study. Eur. J. Clin. Nutr. 1996; 50(Suppl. 2): S4-8.

15 World Health Organization (WHO). Energy and Protein Requirements: Report of a Joint FAO/WHO/UNU Expert Consultation on Energy and Protein Requirements. Technical Report Series No. 724. Geneva: WHO, 1985.

16 Beaton GH, Milner J, Corey P, McGuire V, Cousins M, Stewart $\mathrm{E}$, et al. Sources of variance in 24-hour dietary recall data: implications for nutrition study design and interpretation. Am.J. Clin. Nutr. 1979; 32: 2546-9. 